\title{
Д.Л. Устименко
}

\section{ОБОСНОВАНИЕ АНТРОПОГЕНЕТИЧЕСКОГО ВОПРОСА В ФЕНОМЕНОЛОГИИ Э. ГУССЕРЛЯ}

\footnotetext{
Рассматриваются ключевые антропогенетические интуиции феноменологии Э. Гуссерля. Познание антропогенеза артикулируется им исходя из перспективы «метафизики фактичности». Это означает, что пра-структуры трансцендентальной субъективности, могущие открываться в рефлексии с очевидностью, сами в себе показывают а priori собственной возможности. Антропогенез рассматривается в ракурсе самоданности сознания, собственный генезис которого, согласно Гуссерлю, имеет мгновенный «толчковыци» характер.

Ключевые слова: антропогенез, метафизика фактичности, трансиендентальная субъективность, изначальность, творение.
}

Следует признать, что теме антропогенеза в феноменологии не уделено достаточного внимания. При широком анализе генетических тем в ней едва ли присутствует сам термин «антропогенез», между тем обсуждаемые вопросы о «границе» антропологического, субъективного, абсолютного сознания прямо указывают именно на его событие-реальность. Статус термина и в целом акцентуации проблемы антропогенеза в феноменологии объяснимы спецификой феноменологического дискурса в его приверженности «строгому» методу, не позволяющему произвольно решать подобные «метафизические» вопросы.

Антропогенез действительно есть «метафизическая» проблема, остающаяся за-предельной вечной тайной, которая тем не менее может иметь феноменологическое прояснение. Критерий его познания точно выражен К. Кэлером: если исходить из парадигмы центрального значения сознания, в отношении к которому «каждое сущее есть то, что оно есть, и откуда определяется, как оно есть» [1. С. 170], то в качестве «носителя метафизического знания, оно остается реально отдаленным от первопричины своей собственной завершенности» [1. С. 170]. Человек как субъект сознания осознает «себя в определениях своей экзистенции и отношении к другим. Таким образом, он может иметь знание только благодаря разуму и стремится развивать его по направлению к метафизическому знанию. Однако «разум» для этого знания есть всегда такая цель, которую оно как знание лишь конечного субъекта никогда не может достичь. Это знание понимается только как ограниченная форма осуществления совершенных разума и действительности. Лишь тогда, когда знание определяется строго по границам, неснимаемым для него в соответствии с условиями ему самому известного в своей конечности разумасубъекта, субъект становится началом и познаваемого вообще, и истинной для него действительности» [1. С. 170]. 
«Метафизичность» проблемы антропогенеза может быть увидена и в том, что в рамках феноменологического подхода исключается возможность познания человеческой природы с ее реальным познанием и способностями, с которой имеет дело антропология. Феноменология не эмпирическая наука. Она «имеет дело исключительно с переживаниями, постигаемыми в интуиции и анализируемыми в чистой сущностной всеобщности, не с эмпирическими апперцепируемыми переживаниями как реальными фактами, т. е. переживаниями переживающих людей или животных» [2. С. 14]. В то же время «априорный характер сущностей не противоречит тому, что созерцание сущности фундировано в созерцании индивидуальных предметностей» [3. С. 206] - именно это и позволяет артикулировать антропогенез в феноменологической перспективе.

Гуссерль неоднократно обращался к теме рождения и происхождения, начиная с «Идей ІІ», но особенно в рукописях 1930 года, развивающих «генеративную феноменологию», где рождение и смерть объявляются «событиями, сущностными для конституирования мира» [4. С. 198]. Он утверждает, что, поскольку феноменологическая сфера ограничена пределами конкретно-субъективной самотемпорализации, процесс рождения находится вне доступного сознанию непосредственного опыта - он конститутивно размещается на его «границах». «Преодоление» этой познавательной границы решается им через выход к проблеме Дома, Другого и в целом - к аспекту интерсубъективности. В его рамках «процесс рождения» «вовлечен в генеративную передачу смысла, интегрирован в усвоение и неусвоение нормативных структур, которые предвосхищаются предшественниками и пересматриваются последователями через традиции, истории, ритуалы, восстания, разрывы поколений, обновления, обряды перехода и т. д.» [4. С. 199]. Идейные ходы Гуссерля, касающиеся темы происхождения, затрагивают целый спектр вопросов. Среди них и история мирового знания о происхождении, и проблемы трансгрессии, и прояснение модусов оригинальной недоступности и непостижимости «чужого», и со-конституирование «чужой» геоисторической сферы, и обязательной «даже для феноменологии» исторической плотности «своего». В его работах имеются анализы «границ» аналогизирующей аппрезентации животности, феноменологической «запредельности» животности для человеческого сознания, несущностной «пограничности» животных и людей, смысла «живого тела», гендерных различений, конституирования понятий нормальности и анормальности, рассогласованности и согласованности, возможности объективации границы, идеи телеснодушевной целостности человека.

И все же нельзя признать, что данная тема получила в творчестве Гуссерля всестороннее и систематическое обоснование. Соотнесенная с феноменологическим замыслом и в какой-то мере определенная в смысловом статусе, она осталась без окончательного разрешения и «последнего слова». Ведь если смысл, а значит Истина, истинное, образуется «из соотнесенности», на границе с Иным - на «заре» истории, а для феноменологии как учения о человеческой трансцендентальной субъективности, совпадающей со «всеохватывающей жизнью» и «историей», Первоиным может быть только антропогенез, поскольку ее сознание - это сознание человека, то уместно 
спросить, насколько осуществлено в ней то «последнее эпохе», тот «радикальный шаг самоисключения», позволивший бы выйти за свои пределы и из «бесконечного горизонта» осмыслить себя в идентичности к Нему? По слову К. А. Свасьяна, «тогда уже ретенция, испытующая меру собственной дальнозоркости, натыкалась бы не на «черную ночь» (выражение Гуссерля), для которой «нам не хватает слов», а на апперцептивные озарения памяти, охватывающей ряд модификаций сознания вне круга актуально данной эгоцентричности. И если верно то, что феноменология обнаруживает «вещь» как горизонт возможностей, то позволительно говорить о горизонте возможностей самой феноменологии, по отношению к которому ее актуализованная форма выглядит всего лишь как начальная черновая проба» [5. С. 192]. Подмечено, что этот «трудный вопрос воспоминания» осилен Гуссерлем в последнем радикальнейшем эпохе 26 апреля 1938 года.

Предельный «исторический» или, можно сказать, перво-темпоральный источник «трансцендентального» сознания - это и есть антропогенетический демаркационный смысл самой феноменологии, связанный с подлинно метафизическими трудностями его определения. От познания этого «метафизического» источника, по сути, зависит не только самообоснование феноменологии, ее возможности, но, обоюдно, и статуса обосновывающегося в ней познания Феноменов, в том числе познания антропогенеза, от которого сама она «приобретает» полное обоснование. В этом плане феноменологическое познание антропогенетично, «метафизично», и это требует пояснения. Оставаясь в закрытости круга, в его, на первый взгляд, «темной», онтической, истине, Гуссерль принимает вызов этой «метафизичности» и пытается посвоему преодолеть его антиномичность и «бессмысленность». С одной стороны, он признает невозможность выхода из круга. Поскольку «каждое содержание осознается только через направленный на него акт схватывания, то тотчас возникает вопрос о сознании, в котором осознается этот акт схватывания, который ведь сам есть содержание, и бесконечный регресс неизбежен. Если, однако, каждое «содержание» «первично осознается» («urbewußt») в себе и с необходимостью, то вопрос о дальнейшем формирующем данности (gebenden) сознании будет бессмысленным» [6. С. 140]. Однако именно на этой почве «имманентности» Гуссерль и намечает развертывание своей «подлинной» феноменологической метафизики, обращенной к фундаментальным вопросам первоначал и первоусловий - метафизики фактичности. Вопрос антропогенеза, на наш взгляд, образует «ядро» ее системноформирующего характера. Поэтому для определения возможностей и перспективы феноменологии антропогенеза следует обратить внимание на ее специфику.

Известно, с каким невероятным напряжением эта метафизика как перспектива познания «собственной возможности» - возможности разума/тела (человека) решалась Гуссерлем. Она имеет множество измерений, но в целом посвящена усмотрению трансцендентальных перво-источников, причем не только сознания, но и шире - пра-феноменов «субъективности», в которой проблема телесности имеет не менее решающее значение. При этом, конечно же, вопрос о сознании для феноменологической метафизики и антропологии является ключевым, поэтому требует особого внимания. 
Трудность в том, что прото-событие сознания не есть безжизненное событие, но, напротив, - яйное исполнение. Сознание, по Гуссерлю, «первоначально возникает не из опыта - в смысле ассоциативной апперцепции, в которой конституируется единство многообразия связей, но из жизни (она есть то, что она есть не для Я, но само Я)» [7. С. 141]. Это означает, что сознание исполняется не из собственной активности, условия возможности которой сами не вытекают из активности, но - из «предвременения (Vorzeitigung) изначально пассивного допущения протекания (Stromenlassen) анонимного смысла бытия, который еще не является различенным» [7. С. 142]. Согласно исследованиям Л. Ладгребе, это «глубинное измерение» абсолютной трансцендентальной субъективности «не может быть схвачено феноменологической рефлексией» [7. С. 138] - в то же время «оно является первоосновой для всех на нем выстраивающихся конститутивных исполнений. Оно есть абсолютное основание для всякого встречающегося трансцендентного, поскольку без него никакой интенциональный опыт не может быть исполнен. В этом смысле универсальная «жизнь сознания» является, по анализу К. Хельда, «пра-феноменом, в котором все, что может быть названо феноменом, в некотором смысле всегда имеет свой источник. Оно есть пребывающе-текущее самоприсутствие (stehed-stromende Selbstgegenwart), иными словами, оно присутствует для самого себя как текущее абсолютное Я в его пребывающе-текущей жизни» [7. С. 140]. Это «Глубинное»- метафизическое - измерение феноменологического сознания конституировано «первичной пассивностью пра-начальных синтезов сознания времени»: оно конституирует себя как темпоральное и приходит к сознанию себя самого как «абсолютного потока сознания». Последнее и есть конечное исполнение феноменологической редукции как «достижение последнего основания возможности опыта вообще» [7. С. 39]. Характеристика сознания в метафизических категориях «жизни» и «источника» отражается и на фундаментальном понятии «конституирования», которое оказывается не столько «смыслопридаванием», сколько «сотворением», «допущением-явиться». В позднем творчестве Гуссерля жизнь сознания описывается в понятиях «творения», «со-творения» и, что особенно антропогенетически примечательно, - «события». Им высказывается мысль о ее «толчковом» первогенезисе. «Я открывает себя само лишь в некотором трансцендентальном генезисе в качестве трансцендентальной истории. Я «создается», появляется «непостижимый толчок», появляются различные ощущения, аффектации, направленные на Я, реакции, Я-акты и т. Д.» [7. С. 152]. И здесь возникают самые сущностные вопросы-выводы об антропогенезе. Согласно Л. Ландгребе, понятие «непостижимости толчка» сознания означает его «не-темпоральность», «не-случайность» и «абсолютную фактичность».

В этих предельных гранях своего самоистолкования феноменология встречается с проблемой собственной идентичности. И тогда уместными оказываются выводы Л. Ладгребе: фундаментальными функциями пассивного до-конституирования трансцендентальной субъективности являются «функции телесности»; «протекающее прото-событие «трансцендентальной субъективности» должно пониматься как креативный процесс [7. С. 150]. 
Проблему возможности феноменологии как «метафизики в новом смысле» можно, по утверждению Л. Тангели, описывать в категориях «иррациональности трансцендентальных фактов» [8. С. 203]. Здесь в первую очередь имеются в виду проблемы «смерти, судьбы», а также проблемы возможности «подлинной человеческой жизни и проблемы «смысла» истории и вообще этико-религиозные проблемы» [9. С. 199]. Антропогенез, естественно, входит в перечень «иррациональных» проблем. Их решение определяется идеей видения всего «фактического»на «возможном», «эйдетическом» уровне. Сознание, по Гуссерлю, «может мыслить само себя как существующее иначе (anders seined), но абсолютно дано само себе как сущее. Полагание (Setzung) его инобытия (Andersseins) в качестве своего условия имеет полагание его [собственного] бытия» [8. С. 204]. Исходя из этого, «сущность (Essenz) каждой монады неотделима от монадической экзистенции (monadische Existenz)». Или еще определеннее: «Все монадические возможности являются daseinсоразмерными в отношении монадических действительностей» [8. C. 204]. Антропогенетичность этих идей имеет не только методологическое измерение, указывая на невозможность «трансцендентального сознания», в его «эйдетических возможностях выйти за пределы своего фактического бытия» [8. С. 205]. Они имеют и глубокое онтологическое измерение. В «трансцендентальном» плане решающим становится различие между необходимыми и случайными фактами. Как замечает М. Белоусов, «абсолютно изначальной в контексте этого различия является не эйдетическая, а фактическая ирреальность. По отношению к факту cogito уже нельзя говорить об априори, которое делало бы его возможным, скоpee, этот факт есть условие собственной возможности. Факту cogito ничто не предшествует, но как абсолютное начало он сам оказывается у Гуссерля предшествующим многообразию априори, образует своеобразное априори априори» [3. С. 216].

Именно посредством так понимаемого сознания, по Гуссерлю, «мы приходим к последним «фактам» (Tatsachen») - прафактам, к последним необходимостям, «пранеобходимостям». Он пишет: «Я думаю о них, я переспрашиваю и наконец прихожу к ним от мира, который я уже «имею». 〈..> - Я являюсь прафактом в этой цепочке размышлений, я узнаю, что к моей фактической способности сущностной вариации (Wesensvariation) и т. д., в моем фактическом переспрашивании (Ruckfragen) даются мне эти и те собственные прасостояния (Urbestande) как праструктуры мой фактичности. А также и то, что я ношу в себе ядро праслучайного (Urzufalligen) в сущностных формах, в формах осуществляемого функционирования (vermoglichen Funktionerens), в которых кроме того фундированы мирские сущностные необходимости (Wesensnotwedigkeiten)» [8. С. 205]. Выявляя в сущностных формах «ядро праслучайного», Гуссерль впервые снимает разделение трансцендентальной феноменологии и метафизики фактичности, что, на наш взгляд, имеет серьезные антропогенетические последствия. 


\section{Лuтература}

1. Кэлер К. Сознание и его феномены: Лейбниц, Кант и Гуссерль // Horizon. Феноменологические исследования 2014. Т. 3 (1).

2. Гуссерль Э. Собрание сочинений. Т. 3 (1). Логические исследования. Т. ІІ (1) / пер. с нем. В.И. Молчанова. М.: Гнозис, Дом интеллектуальной книги, 2001.

3. Белоусов М.A. Априори и фактичность в феноменологии Гуссерля // Многообразие априори. Материалы международной конференции на философском факультете РГГУ 19 20 апреля 2012 г. / под ред. А.Н. Круглова. М.: «Канон+» РООИ «Реабилитация», 2013.

4. Стейнбок Э. Пограничные феномены и пограничность опыта // Топос. 2009. № 2$3(22)$.

5. Свасьян К.А. Феноменологическое познание. Пропедевтика и критика. 2-е изд. М.: Академический Проект; Альма Матер, 2010.

6. Гуссерль Э. Собрание сочинений. T: I: Феноменология внутреннего сознания времени / пер. с нем.;сост., вступ. статья, пер. В.И. Молчанова. М.: Гнозис, 1994.

7. Ладгребе Л. Проблема пассивного конституирования // Horizon. Феноменологические исследования. 2012. Т. 1 (1).

8. Тангели Л. Феноменология и категории опыта // Horizon. Феноменологические исследования. 2012. Т. 2(1).

9. Гуссерль Э. Картезианские медитации / пер. с нем. В.И. Молчанова. М.: Академический Проект, 2010.

Ustimenko Dmitry L. North Caucasian branch of the Moscow Technical University of Communications and Informatics (Rostov-on-Don, Russian Federation). DOI 10.17223/1998863X/30/18

THEORETICAL JUSTIFICATION ANTHROPOGENETIC QUESTION IN
PHENOMENOLOGY OF E. HUSSERLS

Keywords: anthropogenesis, metaphysics of factionist, transcendental subjectivity, beginning, creation.

In the question about the origin of man E. Husserl remains methodologically consistent, offering a range of original phenomenological solutions. An important part of understanding anthropogenesis is clarification border aspects of consciousness. The problem of anthropogenesis is a rationale for the ability of the mind/body through the appreciation of the transcendental first sources, and not only consciousness, but also, more broadly, the great phenomena of «subjectivity». Anthropogenesis is considered from the perspective of consciousness, own the Genesis of which, according to Husserl, is an instant «jog» in nature. Husserl argues that, because the phenomenological sphere constrained within specific subjective temporal, the process of birth is available outside the immediate consciousness of the experience - it is constitutive for its «borders». The overcoming of this cognitive boundaries is solved them through the exit to the problem of the House, the Other, and in General - to the aspect of intersubjectivity. In the framework of the birth process involved in generative transmission of sense, integrated in the absorption and new regulatory structures that anticipate predecessors and revised followers through traditions, stories, rituals, breaks, generations, rites of passage and so on. Ideological moves Husserl concerning themes of origin, covering a range of issues. Among them the history of world knowledge about the origin, and the problem of transgression, and clarification of the modes of the original inaccessibility and incomprehensibility «alien», and co-constituting the «foreign» geohistorical areas, and mandatory even for phenomenology historical density of «his». His works are studies of «borders» analogical appresentation animal statement, phenomenological «transcendent» animal statement to the human consciousness, non-entity «boundaries» of animals and people, meaning «living body», gender distinctions, constituting concepts of normality and abnormality, coherence and consistency, the possibility of objectivation of the border, the idea of bodily-mental integrity of a person.

\section{References}

1. Kahler, K. (2014) Soznanie i ego fenomeny: Leybnits, Kant i Gusserl' [Consciousness and its phenomena: Leibniz, Kant and Husserl]. Horizon. Fenomenologicheskie issledovaniya. 3 (1). Pp. 169190. 
2. Husserl, E. (2001) Sobranie sochineniy [Collected works]. Vol. 3 (1). Translated from German by V.I. Molchanov. Moscow: Gnozis.

3. Belousov, M.A. (2013) [A priori and factuality in Husserl's phenomenology]. Mnogoobrazie apriori [Variety of a priori.]. Proc. of the International Conference of the Faculty of Philosophy of Russian State Humanitarian University. April 19th to 20th, 2012. Moscow: Kanon+, ROOI Reabilitatsiya. 4. Steinbock, E. (2009) Pogranichnye fenomeny i pogranichnost' opyta [Border phenomena and marginality of experience]. Topos. 2-3 (22).

5. Svasyan, K.A. (2010) Fenomenologicheskoe poznanie. Propedevtika i kritika [Phenomenological knowledge. Propaedeutics and criticism]. Moscow: Akademicheskiy Proekt; Al'ma Mater.

6. Husserl, E. (1994) Sobranie sochineniy. T. I: Fenomenologiya vnutrennego soznaniya vremeni [Collected Works. T. I: Phenomenology of the inner consciousness of time]. Translated from German by V.I. Molchanov. Moscow: Gnozis.

7. Langrebe, L. (2012) Problem of Passive Constitution. Translated by N. Artemenko. Horizon. Fenomenologicheskie issledovaniya - Horizon. Studies in Phenomenology. 1 (1).

8. Tangeli, L. (2012) Phenomenolgy and Categories of Experience. Translated by D. Kononets. Horizon. Fenomenologicheskie issledovaniya - Horizon. Studies in Phenomenology. 2(1).

9. Husserl, E. (2010) Kartezianskie meditatsii [Cartesian meditation]. Translated from German by V.I. Molchanov. Moscow: Akademicheskiy Proekt. 